\title{
Simultaneous quantitative analysis of biologically important Amaryllidaceae alkaloids in Narcissus tazetta L. subsp. tazetta by HPLC/PDA
}

\author{
Çiğgem KARAKOYUN 1 * (D), Nehir ÜNVER-SOMER ${ }^{1}$ (D) \\ 1 Department of Pharmacognosy, Faculty of Pharmacy, Ege University, Bornova 35100 İzmir, Turkey. \\ * Corresponding Author. E-mail: cigdemkarakoyun@gmail.com (Ç.K.); Tel. +90-232-311 25 98; Fax: +90-232-388 52 58.
}

Received: 27 September 2018/ Revised: 15 November 2018/ Accepted: 22 November 2018

\begin{abstract}
The present study was conducted for the quantitative determination of biologically active Amaryllidaceae alkaloids, galanthamine and lycorine, in the bulbs and aerial parts of a subspecies naturally growing in Turkey namely, Narcissus tazetta L. subsp. tazetta collected from Muğla/Turkey. A reverse phase high performance liquid chromatographic method using an isocratic system consisting of trifluoroacetic acid:water:acetonitrile (0.01:90:10) with a flow rate of $1 \mathrm{~mL} / \mathrm{min}$ was carried out. Photodiode array detection was employed to determine the UV-visible spectral characteristics of the alkaloids. Determination of acetylcholinesterase and butyrylcholinesterase inhibitory activities of different parts of mentioned subspecies were accomplished using a microplate assay modified from Ellman's method. This is the first report of the galanthamine content of Narcissus tazetta subsp. tazetta of Turkish origin. $0.0051 \%$ and $0.0055 \%$ galanthamine was detected in the bulbs and aerial parts of the plant, respectively. Also, lycorine was determined as $0.0250 \%$ in the bulbs and $0.0672 \%$ in the aerial parts.
\end{abstract}

KEYWORDS: Amaryllidaceae; alkaloid; galanthamine; lycorine; quantitative determination.

\section{INTRODUCTION}

The genus Narcissus L. is a member of monocotyledonous family Amaryllidaceae, which is well known in horticulture for its ornamental plants and in medicine for the content of biologically active secondary metabolites called Amaryllidaceae alkaloids [1]. These compounds which have numerous bioactivities including analgesic, antiviral, antibacterial, antifungal, antimalarial, antitumor and cytotoxic activities have been increasingly important to the researchers [1-4].

The first attempts to investigate this family with regard to therapeutical potential of the alkaloids have started with the isolation of the first Amaryllidaceae alkaloid, lycorine, from the genus Lycoris [5]. Lycorine, the main representative alkaloid of Amaryllidaceae plants, have come to the forefront with biological activities more particularly with in vitro anticancer efficiency [6]. Research on the medicinal use of these plants gained acceleration in consequence of the discovery of galanthamine with practical application as a long active, selective, reversible anti-acetylcholinesterase inhibitor agent [7]. Galanthamine is currently available in the market, being prescribed to treat Alzheimer's disease [8].

Depending on the increase in demand for galanthamine in medicine, extraction mostly from galanthamine-rich plants, namely Galanthus L. and Leucojum L. species, remained incapable[9]. Various quantitative analyses on different plant species have been performed in an attempt to find out alternative natural galanthamine sources [10]. Narcissus genus has advantages such as being commonly cultivated and hybridized and involving more than 100 varieties containing galanthamine [9-10].

Narcissus genus, is also important having an extensive coverage in exportation from Turkey [11]. Although the economic value of the plant arises from cut flowers, expert plant producers and extensive farming culture of Narcissus tazetta L. subsp. tazetta enable a possible bulb exportation in case of the confirmation of bioactive alkaloid-rich content in these plants.

In this concept, the aim of the present study is to determine galanthamine and lycorine content of the subsequently naturalized plant Narcissus tazetta L. subsp. tazetta collected from Muğla/Turkey and therefore to evaluate its economic and therapeutical value among the Turkish Amaryllidaceae plants. Additionally, for

How to cite this article: Karakoyun Ç, Ünver-Somer N. Simultaneous quantitative analysis of biologically important Amaryllidaceae alkaloids in Narcissus tazetta L. subsp. tazetta by HPLC/PDA. J Res Pharm. 2019; 23(3): 498-505. 
this purpose, acetylcholinesterase and butyrylcholinesterase inhibitor activity assays were performed on total alkaloid extracts of the bulbs and aerial parts of the plant.

\section{RESULTS AND DISCUSSION}

\subsection{Results}

In the present study, quantitative determination was carried out based on the peak areas in chromatograms. Retention times of galanthamine and lycorine (mean $\pm S D n=15$ ) were detected as $7.82 \pm 0.02$ and $5.91+0.048 \mathrm{~min}$ respectively. HPLC chromatograms of total alkaloidal extracts of aerial parts and bulbs are given comparatively with those of standard alkaloids in Figure 1. Linear regression equation $(n=5)$ and the correlation coefficient $(\gamma)$ are given in Table 1 . In the regression equation $y=a x+b ; y$ refers to the peak area and $x$ refers to the concentration of the alkaloid.

Table 1. Linearity Parameters and Limit of Detection/ Limit of Quantification(LOD/LOQ) Determinations by HPLC.

\begin{tabular}{lllll}
\hline Standart & Regression equation & $r$ & $\begin{array}{l}\text { LOD } \\
(\mathbf{S} / \mathbf{N}=3)\end{array}$ & $\begin{array}{l}\text { LOQ } \\
(\mathrm{S} / \mathbf{N}=\mathbf{1 0})\end{array}$ \\
\hline $\begin{array}{l}\text { Galanthamine } \\
\text { Lycorine }\end{array}$ & $\mathrm{y}=66910+542125 \mathrm{x}$ & 0.9994 & 0.3843 & 1.281 \\
$\mathrm{y}=466834+149877 \mathrm{x}$ & 0.9997 & 0.4901 & 1.6337 \\
\hline
\end{tabular}

The results show that Narcissus tazetta L. subsp. tazetta bulbs contain $0.0050-0.0053 \%$ DW galanthamine and $0.0249-0.0251 \% \mathrm{DW}$ lycorine. Also, the aerial parts of the plant contain $0.0050-0.0058 \%$ DW galanthamine and $0.0672-0.0677 \%$ DW lycorine.

Findings of recovery experiments obtained within the context of accuracy studies are given in Table 2 . All the samples were injected three times. "SD" refers to standard deviation and "RSD" to relative standard deviation.

Table 2. Recovery percents of galanthamine and lycorine determined by HPLC.

\begin{tabular}{lccccc}
\hline Compound & $\begin{array}{c}\text { Initial amount } \\
(\boldsymbol{\mu g} / \mathbf{m L})\end{array}$ & $\begin{array}{c}\text { Added amount } \\
(\boldsymbol{\mu g} / \mathbf{m L})\end{array}$ & $\begin{array}{c}\text { Detected amount } \\
(\boldsymbol{\mu g} / \mathbf{m L})\end{array}$ & $\begin{array}{c}\text { Recovery } \\
(\%)\end{array}$ & $\begin{array}{c}\text { RSD } \\
(\mathbf{\%})\end{array}$ \\
\hline \multirow{3}{*}{ Galanthamine } & \multirow{3}{*}{3} & 1.5 & 4.396 & 97.69 & 1.19 \\
& & 3 & 5.964 & 99.33 & 0.98 \\
Lycorine & \multirow{2}{*}{15} & 6.5 & 8.89 & 98.78 & 1.37 \\
& & 15 & 22.418 & 99.64 & 1.2 \\
& & 30 & 29.690 & 98.97 & 0.98 \\
& & 44.269 & 98.37 & 0.37 \\
\hline
\end{tabular}

The precision of the method was validated by intra-day and inter-day measurements as given in Table 3. The same concentrations of calibration standards and the same equations were used for repeatability tests. Determinations have been performed in triplicate for each concentration. Inter-day assays were carried out in two successive days by different analysts.

Another validation parameter, robustness test was performed by modifying temperature settings (See Table 4.). Analyses at 20, 25 and $30^{\circ} \mathrm{C}$ for each standard in five different concentrations resulted in consistent findings.

The in vitro bioactivity assay results indicated that the bulbs of the plant are effective inhibitors for AChE enzyme (see in Table 5). The aerial parts also showed noticeable inhibition on AChE. Both samples analyzed for their BuChE inhibition and showed similar potency. Considering the whole plant; we can conclude that total alkaloidal extracts have significant inhibition on the enzyme AChE. 


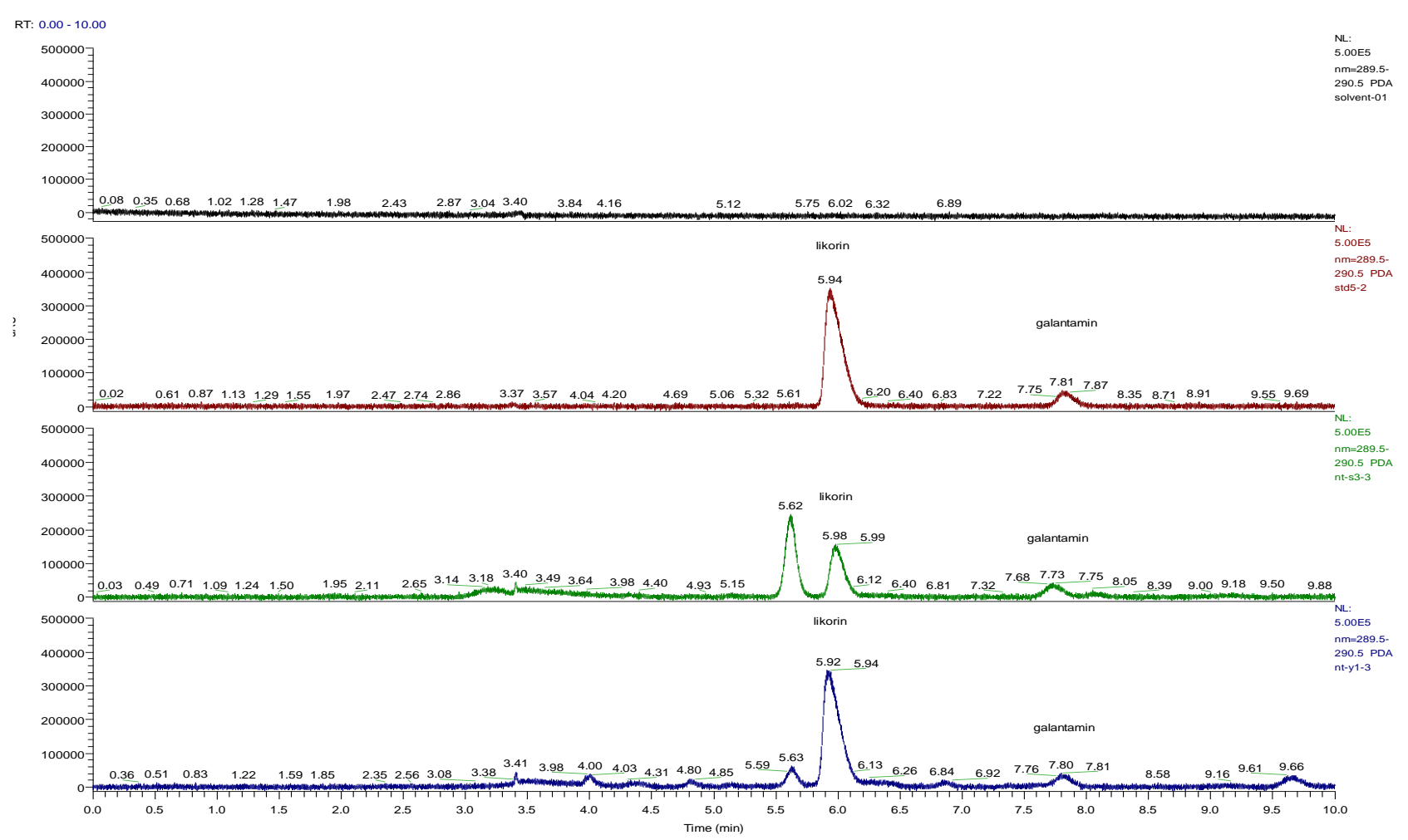

Figure 1. HPLC chromatograms of the blank, the standard solution, total alkaloidal extract of the bulbs and the aerial parts of N. tazetta L. subsp. tazetta that are shown in black, red, green and blue, respectively.

Table 3. Intra-day and inter-day repeatability data.

\begin{tabular}{cccc}
\hline Compound & Amount injected $(\mu \mathrm{g} / \mathrm{mL})$ & $\begin{array}{c}\text { Intra-day repeatability } \\
\text { RSD }(n=5)(\%)\end{array}$ & $\begin{array}{c}\text { Inter-day repeatability } \\
\text { RSD }(n=5)(\%)\end{array}$ \\
\hline \multirow{4}{*}{ Galanthamine } & 0.39 & 2.2 & 0.2 \\
& 0.78 & 2.1 & 1 \\
& 1.95 & 1.7 & 2.4 \\
& 3.90 & 1.9 & 1.5 \\
Lycorine & 7.80 & 1.4 & 1.1 \\
& 2.22 & 2.4 & 0.9 \\
& 4.44 & 0.6 & 1.2 \\
& 8.87 & 1.2 & 0.7 \\
\hline
\end{tabular}

\subsection{Discussion}

Narcissus is a deeply investigated genus with regard to quantification of galanthamine, which has been the most interesting Amaryllidaceae alkaloid being a prescription drug for years [12-14]. For this purpose, various methods including HPLC, GC, ${ }^{1} \mathrm{H}$ NMR were used [14-17]. Among those, HPLC is commonly known with its reliable, fast and sensitive results. Relevant research verified that accurate quantitative determination of galanthamine in Amaryllidaceae plants is possible by HPLC method (18).

Some Narcissus cultivars including Narcissus "Pipit" (Jonquilla) and Narcissus pseudonarcissus cult. 'Carlton' have been reported as good sources of galanthamine $[14,18,19]$. Although naturalized Turkish plant Narcissus tazetta subsp. tazetta is commonly being produced in a huge area in the country by well-versed experts, there is a lack of knowledge for the content of subspecies collected from the western region [11]. Therefore, it is important to determine the alkaloidal content in the title Amaryllidaceae plant, which is economically valuable. 
Table 4. Robustness data.

\begin{tabular}{|c|c|c|c|c|}
\hline Standart & $20^{\circ} \mathrm{C}$ & $25^{\circ} \mathrm{C}$ & $30 \circ \mathrm{C}$ & $\begin{array}{c}\text { Mean } \\
\text { Concentration } \\
(\mu \mathrm{g} / \mathrm{mL}) \pm S D\end{array}$ \\
\hline \multirow{5}{*}{$\begin{array}{c}\text { Lycorine } \\
\text { concentration } \\
(\mu \mathrm{g} / \mathrm{mL})\end{array}$} & 25.08 & 25.50 & 25.00 & $25.1963 \pm 0.27$ \\
\hline & 31.41 & 31.38 & 31.02 & $31.2703 \pm 0.22$ \\
\hline & 43.02 & 44.24 & 41.17 & $42.8093 \pm 1.55$ \\
\hline & 22.43 & 22.46 & 22.54 & $22.4783 \pm 0.06$ \\
\hline & 44.01 & 44.03 & 44.02 & $44.0190 \pm 0.01$ \\
\hline \multirow{5}{*}{$\begin{array}{l}\text { Galanthamine } \\
\text { concentration } \\
(\mu \mathrm{g} / \mathrm{mL})\end{array}$} & 4.90 & 4.99 & 4.96 & $4.951+0.05$ \\
\hline & 5.05 & 4.97 & 5.01 & $5.010 \pm 0.04$ \\
\hline & 10.43 & 10.99 & 10.22 & $10.546 \pm 0.40$ \\
\hline & 3.97 & 3.98 & 3.85 & $3.938+0.07$ \\
\hline & 7.49 & 7.59 & 7.38 & $7.487 \pm 0.11$ \\
\hline
\end{tabular}

Table 5. Anticholinesterase Activitiy of different extracts of Narcissus tazetta subsp. tazetta from Western Turkey.

\begin{tabular}{cccc}
\hline Extract & Concentration $(\mu \mathrm{g} / \mathrm{mL})$ & AChE Inhibition (\%) & BuChE Inhibition (\%) \\
\hline Bulbs & 1000 & 100 & 85.23 \\
& 100 & 87.13 & 37.96 \\
Aerial Parts & 10 & 58.23 & 23.90 \\
& 1000 & 100 & 92.67 \\
& 100 & 67.47 & 35.06 \\
\hline
\end{tabular}

IC50 values of Galanthamine for $\mathrm{AChE}$ and BuChE inhibitory activities were 0.043 and $0.711 \mu \mathrm{g} / \mathrm{mL}$, respectively.

There have been different quantitative analyses on Narcissus species reported in different countries. Galanthamine percentages for some Narcissus species were previously reported as $0.1117 \%$ fresh weight (FW) in Narcissus confusus Pugsley (Spain), 0.0095\% FW in Narcissus nivalis Graells (Spain), 0.001\% FW in Narcissus obesus Salisb. (Portugal) and 0.005\% FW in Narcissus tazetta L. (Egypt) by isolation [18, 20].

Based on the findings of more recent HPLC analyses, within the range of $0.03-0.33 \%$ dry weight (DW), galanthamine was reported in N. tazetta L. collected from different localities of Iran while the same species collected from Holland was reported as lacking this alkaloid $[13,18]$. It is not surprising, to see a wide range of amounts among those samples of the same species knowing that different climate and soil features affect the secondary metabolite profile of plants [14,21].

Since an alteration of alkaloidal content depending on the locality had been previously reported in the literature, we decided to investigate the contents of lycorine and galanthamine and therefore evaluate the therapeutical potential of this subspecies as a source of biologically active Amaryllidaceae alkaloids.

Previous alkaloid quantifications on Narcissus species collected in the flowering period, resulted in higher content in bulbs when compared to the aerial parts [17]. On the contrary, our findings showed that the accumulation of these alkaloids was mostly in the aerial parts.

There has been an isolation study on Narcissus tazetta subsp. tazetta bulbs collected from Southern Turkey [22]. In the light of this information, it is possible to state $0.6 \% \mathrm{DW}$ galanthamine in the mentioned subspecies calculated through isolation findings. Besides this, previous results of lycorine quantification by HPLC show that; the plant sample obtained from the Northwest region of Turkey (supplied by an export firm) contained lycorine as $0.089 \%$ DW [23].

Taking into consideration the dynamic secondary metabolite profile in the plant based on the lifecycle, it is not surprising to determine higher alkaloid quantities in aerial parts of the plant collected in the last term of the flowering season. In furtherance of our results, Narcissus confusus Pugsley collected from Spain has been investigated in terms of galanthamine-type alkaloid content in different developmental stages and leaves were reported as alkaloid-rich part comparing to the bulbs in flowering senescence period [24].

In summary, this plant contains a remarkable amount of lycorine and detectable levels of galanthamine in different parts. 
Alkaloids, particularly galanthamine, have changeable existence on the occasion of fertilizations [25]. The amounts depend not only on the chemical composition of soil but also growth conditions [16]. Different kinds of cultivation methods [15] and tissue culture methods [26-29] have already been successful to increase the galanthamine level of some other Narcissus species [30]. The title subspecies seems to be interesting for agricultural research, investigating further cultivation methods to enhance alkaloid amounts in the plant.

Total alkaloidal extracts of underground and aerial parts of plant were tested for bioactivity using galanthamine as a positive standard. The results revealed that the extracts of N.tazetta L. subsp. tazetta are significant AChE inhibitors. The variations in enzyme inhibitions, might be due to the differences in alkaloidal concentration in various parts of the plant. Also, different dispersion of alkaloids in organs influences the total bioactivity.

\section{CONCLUSION}

To the best of our knowledge, this is the first report on the quantification of galanthamine in Narcissus tazetta subsp. tazetta collected from Turkey. This report is important to evaluate this subspecies as a candidate to be used as a source of bioactive compounds with several cultivation modifications.

The method used in this study is verified by validation assays. Results proved that the extraction procedure was appropriate and the selected HPLC method was a fast and reliable technique for galanthamine and lycorine quantifications. Alkaloidal levels in the different parts of the plant are in compliance with the relevant above-mentioned literature data.

\section{MATERIALS AND METHODS}

\subsection{Plant material}

Narcissus tazetta L. subsp. tazetta was collected during the flowering period from Akçapınar/Muğla. A voucher specimen is deposited in the Herbarium of Ege University, Faculty of Pharmacy, Department of Pharmacognosy with the number of 1596. The plant material was identified by Prof. Dr. Mustafa Ali ÖNÜR (Ege University, Faculty of Pharmacy).

\subsection{Chemicals and solvents}

External standards were used in the form of salts: galanthamine hydrobromide and lycorine hydrochloride (Sigma Aldrich) as part of the quantification analysis method which is based on peak areas. Trifluoroacetic acid (TFA, Merck); HPLC grade acetonitrile (LabScan Analytical Sciences) and double-distilled water were used. Other chemicals and solvents used in the present study were analytically pure.

\subsection{HPLC/PDA}

HPLC instrumentation involves a chromatographic system (Thermo Scientific Accela HPLC Systems), including a quaternary pump, a degasser and an autosampler, coupled with a photodiode array detector (PDA, Thermo Scientific Accela PDA Detector). Chromatographic separation was carried out using a Hichrom $5 \mathrm{C} 18$ analytical column $(4.6 \mathrm{~mm} \times 250 \mathrm{~mm}, 5 \mu \mathrm{m}$ particle size $)$ at $25^{\circ} \mathrm{C}$. The run was performed at a flow rate of $1 \mathrm{~mL} / \mathrm{min}$, using isocratic system with a mobile phase of trifluoroacetic acid:water: acetonitrile (0.01:90:10) and was monitored at $290 \mathrm{~nm}$ by PDA detector. Data acquisition and processing were performed with Thermo Xcalibur Roadmap software.

\subsection{Preparation of sample solutions}

$200 \mathrm{mg}$ of air-dried and powdered plant material (aerial parts and bulbs) were macerated with $5 \mathrm{~mL}$ of $2 \% \mathrm{HCl}$ solution using an ultrasonic bath at $40{ }^{\circ} \mathrm{C}$ for 5 hours. After maceration; $1 \mathrm{~mL}$ of ammonia and $4 \mathrm{~mL}$ of deionized water was added to the extract. The alkaline extract was centrifugated at $5000 \mathrm{rpm}$ for $10 \mathrm{~min}$. The supernatant was transferred to a volumetric flask and adjusted to $10 \mathrm{~mL}$ with deionized water. $3 \mathrm{~mL}$ of the fluid was charged to a prepacked column containing diatomaceous earth (Extrelut ${ }^{\circledR}$, Merck). Elution of the column commenced after 10 minutes which was performed using $5 \mathrm{~mL}$ portions of chloroform in three parts. The organic solvent was evaporated in vacuo and the residue was dissolved in $1 \mathrm{~mL}$ of $1 \%$ TFA solution. The extract was filtered through a $0.45 \mu \mathrm{m}$ filter and injected into the HPLC system. 


\subsection{Preparation of standart solutions}

$1 \mathrm{mg}$ of salt form of each external standard was dissolved with $1 \mathrm{~mL}$ of $0.1 \%$ TFA solution. Five different concentrations of these solutions were obtained by diluting with the same solvent. Dilutions were made within the range of 2.5- $50 \mu \mathrm{g}$ and 1-15 $\mu \mathrm{g}$ for lycorine and galanthamine, respectively. Concentrations on the calibration curve were calculated in terms of the base forms of the alkaloids.

\subsection{Validation studies}

In order to validate the assay; linearity, recovery studies as a part of accuracy, intra-day and inter-day repeatability studies, as a part of precision, robustness controls were carried out. For linearity studies, stock solutions containing $1 \mathrm{mg} / \mathrm{mL}$ of lycorine hydrochloride and $1 \mathrm{mg} / \mathrm{mL}$ of galanthamine hydrobromide were prepared using $0.1 \%$ TFA separately. Dilutions were carried out using the same solution at concentrations; $2.5,5,10,25,50 \mu \mathrm{g} / \mathrm{mL}$ and $1,2.5,5,7.5,15 \mu \mathrm{g} / \mathrm{mL}$ for lycorine hydrochloride and galanthamine hydrobromide, respectively (Concentrations were calculated in terms of the base forms of the alkaloids as mentioned before.)

On the purpose of verifying the accuracy of this method, recovery experiments were conducted. The same procedure as described in Section 4.4. was applied with a modification including the spiking of lycorine and galanthamine in the acidic extract in amounts given in Table 2.

\subsection{Anticholinesterase activity assay}

During bioactivity assays, the increase of absorbance based upon the concentration of compounds was measured at $405 \mathrm{~nm}$ using Molecular Devices Versamax Tunable microplate reader. The enzyme acetylcholinesterase and butyrylcholinesterase are derived from electric eel (Type VIs, Lyophilized powder) and Equus caballus, respectively. Acetylthiocholine iodide (ATCI), butyrylthiocholine iodide (BTCI) and Ellman's reagent (5,5'-dithiobis-(2-nitrobenzoic acid) (DTNB)) were purchased from Sigma. All solvents and reagents take part in this study have the feature of analytical grade.

Different concentrations of total alkaloidal extracts $(1000,100$ and $10 \mu \mathrm{g} / \mathrm{mL})$ were prepared in $\mathrm{MeOH}$. A modified assay originated from Ellman's colorimetric method (31) was performed as described previously(32). Galanthamine was used as a positive standard. Results were given as percentage for extracts and were shown in Table 5. The analysis was performed in triplicate for each sample.

Acknowledgements: Thanks are extended to Prof. Dr. Mustafa Ali ÖNÜR (Department of Pharmacognosy, Faculty of Pharmacy, Ege University) for the collection and identification of the plant material and FABAL (Pharmaceutical Sciences Research Centre, Faculty of Pharmacy, Ege University) for their support during experiment process.

Author contributions: Concept -N.US.; Design - N.US., C..K.; Supervision -N.US.; Resource - N.US.; Materials N.US.,Ç.K.; Data Collection \&/or Processing - N.US., Ç.K.; Analysis \&/or Interpretation - N.US., Ç.K.; Literature Search - Ç.K.; Writing - Ç.K; Critical Reviews - N.US., Ç.K.

Conflict of interest statement: The authors declared no conflict of interest in the manuscript.

\section{REFERENCES}

[1] Nair JJ, Bastida J, Codina C, Viladomat F, van Staden J. Alkaloids of the South African Amaryllidaceae: A review. Nat Prod Commun. 2013; 8(9): 1335-1350. [CrossRef]

[2] Nair JJ, van Staden J. Pharmacological and toxicological insights to the South African Amaryllidaceae. Food Chem Toxicol. 2013; 6: 262-275. [CrossRef]

[3] Nair JJ, van Staden J. Traditional usage, phytochemistry and pharmacology of the South African medicinal plant Boophone disticha (L.f.) Herb. (Amaryllidaceae). J Ethnopharmacol. 2014; 151(1): 12-26 [CrossRef]

[4] Cimmino A, Masi M, Evidente M, Superchi S, Evidente A. Amaryllidaceae alkaloids: Absolute configuration and biological activity. Chirality. 2017; 29: 486-499. [CrossRef]

[5] He M, Qu C, Gao O, Hu X, Hong X. Biological and pharmacological activities of amaryllidaceae alkaloids. RSC Adv. 2015; 5: 16562-16574. [CrossRef]

[6] Dasari R, Banuls LMY, Masi M, Pelly SC, Mathieu V, Green IR, van Otterlo WAL, Evidente A, Kiss R, Kornienko A. C1,C2-ether derivatives of the Amaryllidaceae alkaloid lycorine: Retention of activity of highly lipophilic analogues against cancer cells. Bioorg Med Chem Lett. 2014; 24: 923-927. [CrossRef] 
[7] Su J, Liu H, Guo K, Chen L, Yang M, Chen Q. Research advances and detection methodologies for microbe-derived acetylcholinesterase inhibitors: A systemic review. Molecules. 2017; 22(1): pii 176. [CrossRef]

[8] Heinrich M, Teoh HL. Galanthamine from snowdrop - the development of a modern drug against Alzheimer's disease from local Caucasian knowledge. J Ethnopharmacol. 2004; 92: 147- 162. [CrossRef]

[9] Torras-Claveria L, Berkov S, Codina C, Viladomat F, Bastida J. Daffodils as potential crops of galanthamine. Assessment of more than 100 ornamental varieties for their alkaloid content and acetylcholinesterase inhibitory activity. Ind Crops Prod. 2013; 43: 237-244. [CrossRef]

[10] Berkov S, Georgieva L, Kondakova V, Atanassov A, Viladomat F, Bastida J, Codina C. Plant sources of galanthamine: phytochemical and biotechnological aspects. Biotechnol Biotechnol Equip. 2009; 23(2): 1170-1176. [CrossRef]

[11] Uzmay A, Durmaz S, Örümlü AE. A Study on the Problems of Narcissus Farming in Mordoğan. Ege Üniv Ziraat Fak Derg. 2001; 38(1): 39-46.

[12] Selles M, Bastida J, Viladomat, Codina C. Quantitative evaluation of galanthamine and related alkaloids in wild plants and tissue cultures of Narcissus confusus by high performance liquid chromatography. Analysis. 1997; 25: 156158 [CrossRef]

[13] Khonakdari MR, Mirjalili MH, Gholipour A, Rezadoost H, Farimani MM. Quantification of galantamine in Narcissus tazetta and Galanthus nivalis(Amaryllidaceae) populations growing wild in Iran. Plant Genet Resour. 2018; 16(2): 188-192. [CrossRef]

[14] Lubbe A, Pomahacova B, Choi YV, Verporte R. Analysis of metabolic variation and galanthamine content in Narcissus bulbs by 1H NMR. Phytochem Anal. 2010; 21(1): 66-72. [CrossRef]

[15] MoraesCerdeira RM, Burandt CL, Bastos JK, Nanayakkara NPD, Mikell J, Thurn J, McChesney JD. Evaluation of four Narcissus cultivars as potential sources for galanthamine production. Planta Med. 1997; 63(5): 472-474. [CrossRef]

[16] Laura TC, Strahil B, Carles C, Francesc V, Jaume B. Daffodils as potential crops of galanthamine. Assessment of more than 100 ornamental varieties for their alkaloid content and acetylcholinesterase inhibitory activity. Ind Crops Prod. 2013; 43: 237-244. [CrossRef]

[17] Kreh M. Studies on galanthamine extraction from Narcissus and other Amaryllidaceae. In: Hanks GR, (Eds). Narcissus and Daffodil- The genus Narcissus Taylor \& Francis Ltd, New York, 2002, pp. 256-272.

[18] Mustafa NR, Rhee IK, Verpoorte R. Rapid method for determination of galanthamine in Amaryllidaceae plants using HPLC. J Liq Chromatogr Relat Technol. 2003; 26(19): 3217-3233. [CrossRef]

[19] Hanks GR. Commercial production of Narcissus bulbs. In: Hanks GR. (Eds). Narcissus and Daffodil- The genus Naricssus. Taylor \& Francis Ltd, New York, 2002, pp. 53-130.

[20] Abdallah OM. Narcisine, an alkaloid from Narcissus tazetta. Phytochemistry. 1993; 34(5): 1447-1448. [CrossRef]

[21] Ramakrishna A, Ravishankar GA. Influence of abiotic stress signals on secondary metabolites in plants. Plant Signal Behav. 2011; 6(11): 1720-1731. [CrossRef]

[22] Orhan I, Sener B. Bioactivity-directed fractionation of alkaloids from some Amaryllidaceae plants and their anticholinesterase activity. Chem Nat Compd. 2003; 39(4): 383-386. [CrossRef]

[23] Sener B, Koyuncu M, Bingöl F, Muhtar F. Production and bioactive alkaloids from Turkish geophytes. Pure Appl Chem. 1998; 70: 2131.

[24] Lopez S, Bastida J, Viladomat F, Codina C. Galanthamine Pattern in Narcissus confusus plants. Planta Med. 2003; 69: 1166-1168. [CrossRef]

[25] Lubbe A, Choi YH, Vreeburg P, Verporte R. Effect of fertilizers on galanthamine and metabolite profiles in Narcissus bulbs by ${ }^{1} \mathrm{H}$ NMR. J Agric Food Chem. 2011; 59 (7): 3155-3161. [CrossRef]

[26] Bergonon S, Codina C, Bastida J, Viladomat F, Mele E. Galanthamine production in "shoot-clump" cultures of Narcissus confusus in liquid-shake medium. Plant Cell Tissue Organ Cult. 1996; 45(3): 191-199. [CrossRef]

[27] Selles M, Bergonon S, Viladomat F, Bastida J, Codina C. Effect of sucrose on growth and galanthamine production in shoot-clump cultures of Narcissus confusus in liquid-shake medium. Plant Cell Tissue Organ Cult. 1997; 49(2): 129136.

[28] Selles M, Viladomat F, Bastida J, Codina C. Callus induction, somatic embryogenesis and organogenesis in Narcissus confusus: correlation between the state of differentiation and the content of galanthamine and related alkaloids. Plant Cell Rep 1999; 18(7-8): 646-651. [CrossRef] 
[29] Colque R, Viladomat F, Bastida J, Codina C. Improved production of galanthamine and related alkaloids by methyl jasmonate in Narcissus confusus shoot-clumps. Planta Med. 2004; 70(12): 1180-1188. [CrossRef]

[30] Carles C. Production of galanthamine by Narcissus tissues in vitro. In: Hanks GR. (Eds). Narcissus and Daffodil-The genus Narcissus. Taylor \& Francis Ltd, New York, 2002, pp. 215-241.

[31] Ellman GL, Courtney KD, Andres V, Jr., Feather-Stone RM. A new and rapid colorimetric determination of acetylcholinesterase activity. Biochem Pharmacol. 1961;7:88-95. [CrossRef]

[32] Lopez S, Bastida J, Viladomat F, Codina C. Acetylcholinesterase inhibitory activity of some Amaryllidaceae alkaloids and Narcissus extracts. Life Sci. 2002;71(21):2521-2529. [CrossRef]

This is an open access article which is publicly available on our journal's website under Institutional Repository at http://dspace.marmara.edu.tr. 